\title{
Election promises: moving beyond health care
}

I t's been barely 18 months since Canada's federal politicians were last drumming up votes. In the June 2004 election, health care was "the" issue of the campaign, the future of medicare the urgent topic of 30 -second sound bites and leaders' debates. This time around, photo opportunities shifted from health care to day care as candidates sat on tiny chairs, holding babies and proposing either a national day care system or family subsidies, according to political persuasion. Resting on both economics and values, the day care question is no less revealing, ideologically speaking, than recent health care debates. But the care and education of under-fives is unlikely to galvanize an electorate, and so the attention of candidates roved from samesex marriage to housing, education, tax cuts, the environment, the military, gun control, immigration, and Canada's relationship with the United States.

Talk of health care reform has been muted; the "private versus public" debate seems a passion now somewhat spent. The Chaoulli decision sits like an elephant in the living room while candidates voice allegiance to medicare and remind voters about the longstanding role of private service delivery. In this issue ${ }^{1}$ we present responses of the 4 main party leaders to our questions about private clinics, private health insurance, First Nations health issues and physician supply. Largely, the leaders are sticking to their stripes: the Liberals hoping that their \$4I-billion "fix" will hold, reinforced by measures such as wait-time commitments and conditions on funding, the Convervatives keeping the privatization door wedged open with the concept of patients' rights, the NDP affirming its "[refusal] to permit the dismantling" of a single-payer system, and the Bloc tracing health care woes to "draconian" cuts in federal transfers a decade ago and insisting on Quebec's right to find its own solutions.

It is probably safe to predict that health care debates will become more rather than less complex under the next government, as ways and means of making the existing system work better, faster and smarter are sought against the backdrop of the Chaoulli decision and all it implies. Whichever party (or minority coalition) prevails in this winter election, Canadians will have to consider whether they are more committed to the individual's right to the best and speediest care available by public or private means, or to the principle of equity of access to that public good we call health care.

In that vein, we are struck by the findings reported in this issue $^{2}$ of the OECD Health Equity Research Group: after controlling for need, they found that people with higher incomes in the 2I member countries of the Organization for Economic Cooperation and Development were more likely than those with lower incomes to utilize specialist care. This apparent inequity was most pronounced in the United States and Mexico, the 2 OECD countries without universal health insurance coverage, but it is also interesting that the rich were significantly more likely to see a specialist than the poor in all 2I countries regardless of the characteristics of their health care system. Jeremiah Hurley and Michel Grignon ${ }^{3}$ comment that Canadians may take comfort that their access to physician services falls well within OECD norms, but they add a cautionary note: parallel private insurance, which has the highest uptake among the rich, may exacerbate already existing inequities in access to specialist services.

The fact that some of the OECD findings were unexpected - the UK, for example, showed less inequity than other countries with a "blended" public-private system - also reminds us that no health care system can be a perfect guarantor of health care access or of health. It is the ability of a health care system, and of all the social policies that support it, to compensate for socioeconomic and educational disparities, geographic boundaries, cultural influences and environmental factors that will determine the success of health care delivery. Each of those health determinants needs to be recognized and addressed: they all need political air-time. The fact that our federal candidates have shifted voters' attention from medicare reform to other determinants of the health and well-being of the nation is by no means a bad thing. CMAJ

\section{REFERENCES}

I. Eggertson L, Sibbald B. Election 2006: Party leaders debate the health of the nation [news]. CMAJ 2006;174(2):147-9.

2. van Doorslaer E, Masseria C, Koolman X, for the OECD Health Equity Research Group. CMAJ 2006;174(2):177-83.

3. Hurley J, Grignon M. Income and equity of access to physician services. CMAJ 2006;174(2):187-8 